\title{
ARTICLE
}

\section{Dosimetric specification of mixed neutron-photon fields at Czech interim stores for spent nuclear fuel}

\author{
Jana Smoldasova $^{\mathrm{a}^{*}}$, Monika Farnikova ${ }^{\mathrm{b}}$, Ondrej Kvasnicka ${ }^{\mathrm{b}}$, Petr Pokorny ${ }^{\mathrm{c}}$ and Michal Konecny ${ }^{\mathrm{c}}$ \\ ${ }^{a}$ Czech Metrology Institute, Radiova 1, CZ-102 00 Praha 10, Czech Republic; ${ }^{b}$ Nuclear Power Plant Temelin, CZ-373 05 Temelin, \\ Czech Republic; ${ }^{c}$ Nuclear Power Plant Dukovany, CZ-675 50 Dukovany, Czech Republic
}

\begin{abstract}
The objective was to describe dosimetric characteristics of neutron and photon component of mixed fields at three dry interim stores for the spent nuclear fuel situated in territories of two Czech nuclear power plants. Mixed fields depend mainly on the residual thermal power of the loaded fuel, but they are also influenced by the type of CASTOR casks used in each store. To determine values of ambient dose equivalent rate due to neutrons and photons around CASTOR casks, common area dosemeters were employed. As the neutron component of these fields was dominant, neutron spectra were measured by means of the Bonner spheres spectrometer among a few groups of four casks and on their lids. The values of ambient dose equivalent rate derived from neutron spectra were compared with those obtained by area dosemeters. To give an idea about dosimetric situation at the stores, ranges of ambient dose equivalent rate measured around casks are presented together with ratios of this quantity for neutrons to photons.
\end{abstract}

Keywords: Bonner sphere spectrometer; area dosemeter; dry interim store for spent nuclear fuel; CASTOR cask; residual thermal power

\section{Introduction}

Two Czech nuclear power plants (NPP), Dukovany and Temelin, cover $40 \%$ of the country's electricity consumption. The Dukovany NPP, operating since 1985, is equipped with four PWR reactors VVER 440, each of $440 \mathrm{MWe}$, now upgraded to $500 \mathrm{MWe}$. The Temelin NPP has two PWR units, each of $1000 \mathrm{MWe}$, which were commissioned in 2000. As the general agreement on the place for building a permanent repository for spent nuclear fuel has not been reached so far, it has been decided to build dry interim stores for spent fuel within the territories of NPPs. The old store was put in commission in 1995 at the Dukovany NPP, but its capacity was limited to 600 tons on account of objections of some residents of a neighbouring village. This store was completely filled in 2005, therefore a new one with a capacity of 1000 tons was built in 2006 in close vicinity. Dry interim store for the Temelin NPP, put in commission in 2011, can accommodate 1370 tons of spent fuel.

Fuel elements at all stores are placed in the cylindrical CASTOR casks designed by the German company NUKEM. CASTORs are at all stores at upright position; the distance between their axes is $3200 \mathrm{~mm}$. Each of the stores is equipped with different type, the old one of Dukovany with CASTOR-440/84 ( $\varnothing 2660 \mathrm{~mm}, \mathrm{H} 4080 \mathrm{~mm}$ ) casks that can accommodate

\footnotetext{
*Corresponding author. Email: jsmoldasova@cmi.cz
}

84 fuel assemblies whose residual thermal power must be less than $19.3 \mathrm{~kW}$. The same number of assemblies can be placed at the CASTOR-440/84M $(\varnothing 2700 \mathrm{~mm}$, $\mathrm{H} 4138 \mathrm{~mm}$ ) in the new store. The CASTOR-440/84 cask has one row of polyethylene rods in the cylindrical body; they serve as a moderator. The CASTOR$440 / 84 \mathrm{M}$ cask has two rows of these rods and also polyethylene layers at the bottom and the lid. At the Temelin NPP, other fuel assemblies are used, so the design of the employed CASTOR-V19 ( $\varnothing 2440 \mathrm{~mm}$, H $5860 \mathrm{~mm}$ ) casks is different. These casks can accommodate 19 fuel assemblies.

At each store, neutron and photon area dosemeters are firmly installed on the walls to enable continual monitoring of dosimetric situation in dependence on the number of loaded casks. In addition to this permanent monitoring a lot of measurements around casks were performed to ensure the correct interpretation of readings of area and personnel dosemeters [1-3]. Determination of ambient dose equivalent rate among casks is extremely important as the whole bodies of the maintenance personnel are irradiated practically from all directions uniformly.

Readings of instruments measuring the photon component of mixed neutron-photon fields around cask are consistent, but instruments measuring neutrons show rather big discrepancies. As the basic information about neutron fields is spectral fluence rate (spectrum), series of measurement were done at the old store in Dukovany 
[1-3] with the Bonner spheres spectrometer (BSS). The neutron component of mixed neutron-photon fields at this store is dominant, so we continued measurements with BSS at other stores.

\section{Experimental tools}

Routine measurements of neutron component of mixed fields around the casks were done with the following neutron area dosemeters:

- LB 6411 (EG \& G Berthold) with a ${ }^{3} \mathrm{He}$ proportional counter inside a $250 \mathrm{~mm}$ low pressure polyethylene sphere with $2 \%$ carbon additive;

- FHT 752 Biorem (Thermo Eberline) with a $\mathrm{BF}_{3}$ tube inside a cylindrical moderator (Ø $208 \mathrm{~mm} \cdot 395 \mathrm{~mm})$; and photon component by:

- FH 40 G-10 (Thermo Eberline);

- RDS-200 (Rados).

The BSS used was manufactured by Centronic Ltd., UK, according to the PTB design and consists of a set of polyethylene spheres (density $0.946 \mathrm{~g} / \mathrm{cm}^{3}$ ) with the following diameters conventionally given in inches $(1$ inch $=2.54 \mathrm{~cm}): 3,3.5,4,4.5,5,6,7,8,10$, and 12 . A spherical $(3.2 \mathrm{~cm}$ active diameter) proportional counter of type SP 9, filled to the pressure of $202 \mathrm{kPa}$ ${ }^{3} \mathrm{He}$ and $101 \mathrm{kPa} \mathrm{Kr}$ served as the thermal neutron detector at the centres of the spheres.

Neutron spectral fluence rates (spectra) $\dot{\Phi}_{E}$ were unfolded from count rates, measured with BSS, using the GRAVEL code from UMG 3.3 package [4]. As an a priori spectrum a fission spectrum extended down to the thermal region was used. Values of ambient dose equivalent rate due to neutrons $\dot{H}^{*}(10)$ were derived using the fluence-to-ambient-dose-equivalent conversion function $[5,6], h^{*}(10, E)$, according to formula:

$$
\dot{H}^{*}(10)=\int_{E_{\min }}^{E_{\max }} h^{*}(10, E) \cdot \dot{\Phi}_{E}(E) \cdot d E
$$

These values served as conventionally true for the comparison with the values indicated by area dosemeters.

The relative uncertainty of the total fluence (over the whole energy range) is $3 \%$ and at partial energy intervals $10 \%$. The uncertainty of the ambient dose equivalent can reach $20 \%$ as the conversion function neutron fluence to ambient dose equivalent strongly depends on neutron energy.

\section{Results and discussion}

At the old store [1-3] and the new one of the Dukovany NPP measurements were performed with area dosemeters at the geometric centres among all groups of four casks $1 \mathrm{~m}$ above the floor and $20 \mathrm{~cm}$ above their lids. These measurements revealed that ambient dose equivalent rates around casks correlated with the residual thermal power (RP) of the loaded fuel. Analogical measurements were carried out at the new store. At the store at the Temelin NPP only five casks casks and not on the lids.

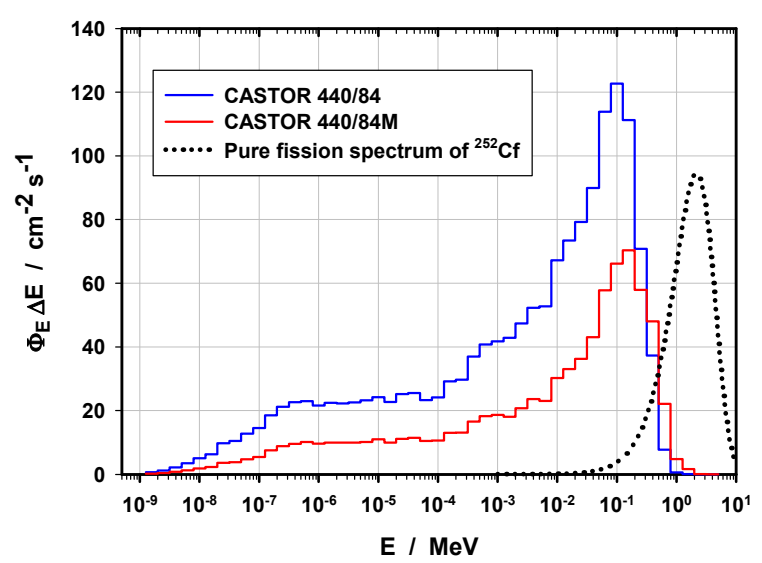

Figure 1. Neutron spectra among four casks. Fission spectrum of ${ }^{252} \mathrm{Cf}$ is included for illustration.

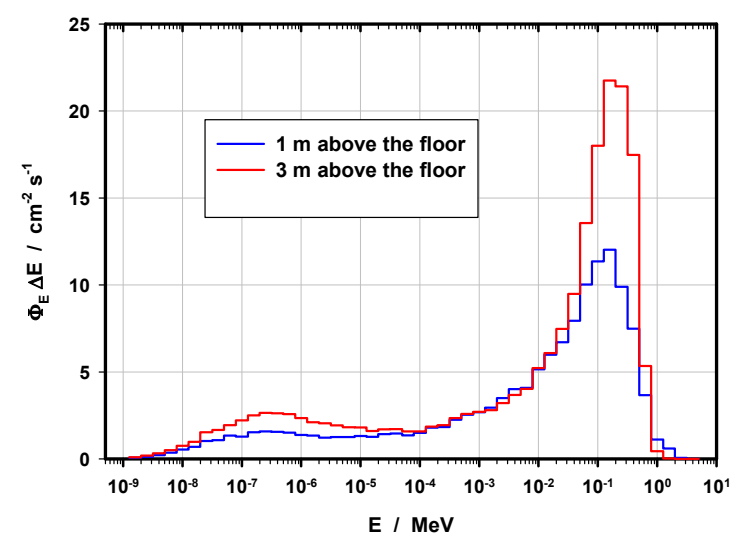

Figure 2. Neutron spectra measured between two CASTORV19 casks.

Neutron spectra measured with BSS among casks are given in Figures $\mathbf{1}$ and $\mathbf{2}$. The thermal part is practically missing because the amount of moderating material in the bodies of the casks is small and the stores are huge almost empty buildings. The fast part of neutron spectra can be characterised as a degraded fission spectrum whose maximum is around $100 \mathrm{keV}$. A pure fission spectrum is added for comparison in Figure 1. Integrals and partial integrals of neutron spectra in Figures 1 and 2 are presented in Table 1. Quantities with the subscript "rel" denote a relative part in the whole energy interval. Neutrons with energies above $1 \mathrm{keV}$ are more than $60 \%$. Their contribution to ambient dose equivalent rate is higher than $90 \%$. From Figure 1 and also Table 1, it is apparent that shielding properties of the CASTOR $440 / 84 \mathrm{M}$ are better than those of CASTOR $440 / 84$ because the ambient dose equivalent rate is lower for the loaded fuel with higher RP.

The spectra of neutrons at the distance of $20 \mathrm{~cm}$ above the centres of the CASTOR lids are given in Figure 3. Their integrals in Table 2 nicely demonstrate the 
improvement of shielding properties due to an additional moderator in the lid of the CASTOR 440/84M. For both CASTOR 440/84 and 440/84M the double lid system shields photons more than neutrons. The ratio of ambient dose equivalent rate of neutrons to ambient dose equivalent rate of photons on the lids is higher than that among casks, see Table 3.

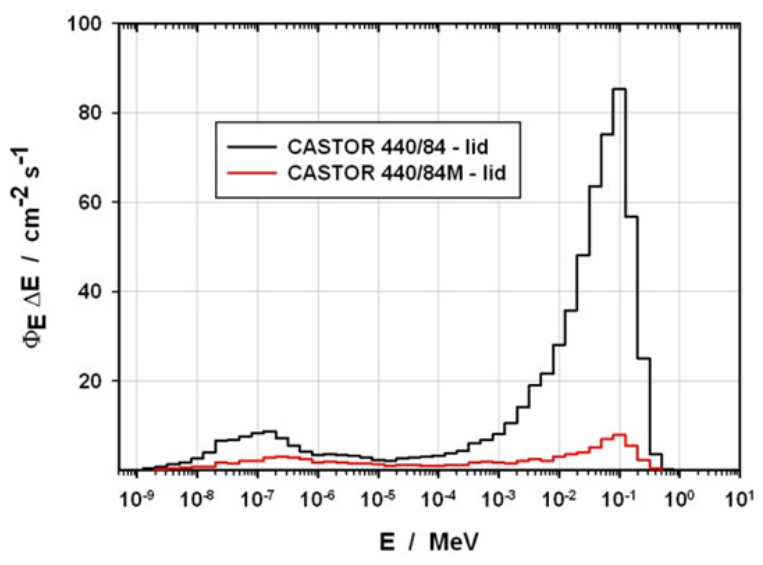

Figure 3. Neutron spectra measured on the CASTORs lids.

In Table 3, the values of ambient dose equivalent rate derived from neutron spectra were compared with the readings (no calibration factor was applied) of two neutron area dosemeters, LB 6411 and FHT 752. Although both instruments comply with the requirements of IEC 61005 standard [7] in ${ }^{252} \mathrm{Cf}$ and ${ }^{241} \mathrm{Am}-\mathrm{Be}$ neutron fields, at the stores of the Dukovany NPP overestimate, FHT 752 more than LB 6411.

Photon component of neutron-photon mixed fields was measured by two types of photon area dosemeters, RDS-200 and FH 40 G-10. In contrast to neutron area dosemeters their readings were practically identical.

Carrying out measurements with BSS is time consuming, so the measurements mapping ambient dose equivalent rate among and above all casks were only done with area dosemeters and one for neutrons LB 6411 was chosen for reference.

The lowest value of total $\dot{H}^{*}(10)$, i.e. neutrons and photons together, found at the old Dukovany store in Summer 2012 was $90 \mu \mathrm{Sv} / \mathrm{h}$ among casks with the lowest RP of the loaded fuel, in other words with the oldest. Analogically, the highest value $426 \mu \mathrm{Sv} / \mathrm{h}$ was measured among casks with the highest value of RP. The ratio of neutron component of the total $\dot{H}^{*}(10)$ to the photon one varied from 4.23 to 5.06 . On the lids, the lowest value of $\dot{H}^{*}(10)$ was $15.1 \mu \mathrm{Sv} / \mathrm{h}$ and the highest was $146.5 \mu \mathrm{Sv} / \mathrm{h}$ and the ratio of neutron component to the photon one being between 11.2 and 39.9. The above stated values are related to the uncorrected readings of LB 6411.

At the new Dukovany store minimum and maximum values did not differ so much because the age of fuel stored in the individual casks does not differ as in the old store. Minimum value of $\dot{H}^{*}(10)$ among casks was $203 \mu \mathrm{Sv} / \mathrm{h}$ and maximum $253 \mu \mathrm{Sv} / \mathrm{h}$. On the lids these values were $16.7 \mu \mathrm{Sv} / \mathrm{h}$ and $20.3 \mu \mathrm{Sv} / \mathrm{h}$. Neutron to photon component ratio varied from 4.04 to 5.06 among casks and from 6.3 to 9.1 on the lids.

In the radiation fields around casks at the Temelin interim store, neutron and photon fractions of ambient dose equivalent rate are similar and the highest value for the total $\dot{H}^{*}(10)$ between two casks was about $80 \mu \mathrm{Sv} / \mathrm{h}$. Filling of the Temelin store with CASTOR V-19 casks is at its beginning, so it was not possible to gather more data.

\section{Conclusions}

Measurements at interim stores for spent nuclear fuel are complicated owing to many administrative obstacles and safety precautions and also owing to changing conditions inside. The number of casks is increasing (except for the completely filled old store of Dukovany) and the residual thermal power of the fuel is decreasing, so it is impossible to repeat the measurement under the same conditions.

As the amount of polyethylene in the bodies of the casks, made from ductile cast iron, is small, neutrons dominate in mixed neutron-photon radiation fields around casks. The thermal part of neutron spectra is practically missing and the fast part can be characterised as a degraded fission spectrum.

The ratio of ambient dose equivalent rate due to neutrons to the same quantity due to photons depends on the residual thermal power of the stored fuel and on the CASTOR cask type. Between the casks at the old Dukovany store, the average of these ratios is $10.9 \pm 0.9$ and on the lids $28 \pm 9$. At the second Dukovany store, neutrons contribute among casks in average $(4.8 \pm 0.3)$ times more, on the lids $(8.3 \pm 0.9)$ times.

The ambient dose equivalent rate of both neutron and photon radiations among casks at the old store is in the range $(90-430) \mu \mathrm{Sv} / \mathrm{h}$ and in $(200-255) \mu \mathrm{Sv} / \mathrm{h}$ at the new one.

In the radiation fields around casks at the Temelin interim store, the neutron and photon fractions of the total $\dot{H}^{*}(10)$ are similar, between two casks together they give $80 \mu \mathrm{Sv} / \mathrm{h}$. Low level of the filling of the store did not allow to present more detailed conclusions.

\section{Acknowledgements}

This work was supported and funded by the Dukovany NPP and the Temelin NPP. The authors gratefully acknowledge their support.

\section{References}

[1] M. Kralik, V. Kulich and J. Studeny, Dosimetry at the interim spent fuel storage facility of the Czech nuclear power plant Dukovany, Journal of Nuclear Science and Technology, Supplement 1, (2000), pp. 762-766. 
Table 1. Integrals of the spectra measured among CASTOR casks

\begin{tabular}{|c|c|c|c|c|c|c|c|}
\hline CASTOR & $\begin{array}{c}\boldsymbol{R P} \\
{[\mathrm{kW}]}\end{array}$ & $\begin{array}{c}\boldsymbol{E}_{\boldsymbol{m i n}} \\
{[\mathrm{MeV}]}\end{array}$ & $\begin{array}{c}\boldsymbol{E}_{\max } \\
{[\mathrm{MeV}]}\end{array}$ & $\begin{array}{c}\dot{\boldsymbol{\Phi}} \\
{\left[\mathrm{cm}^{-2} \cdot \mathrm{s}^{-1}\right]}\end{array}$ & $\dot{\Phi}_{r e l}$ & $\begin{array}{l}\dot{\boldsymbol{H}}^{*}(\mathbf{1 0}) \\
{[\mu \mathrm{Sv} / \mathrm{h}]}\end{array}$ & $\dot{H}^{*}(10)_{r e l}$ \\
\hline \multirow{4}{*}{$440 / 84$} & \multirow{4}{*}{48.92} & $1.0 \mathrm{E}-09$ & $1.0 \mathrm{E}-06$ & 161 & 0.10 & 7.2 & 0.03 \\
\hline & & $1.0 \mathrm{E}-06$ & $1.0 \mathrm{E}-03$ & 403 & 0.26 & 14.7 & 0.05 \\
\hline & & $1.0 \mathrm{E}-03$ & 20. & 993 & 0.64 & 250 & 0.92 \\
\hline & & 1.0E-09 & 20. & 1557 & 1.00 & 272 & 1.00 \\
\hline \multirow{4}{*}{$440 / 84 M$} & \multirow{4}{*}{65.68} & $1.0 \mathrm{E}-09$ & $1.0 \mathrm{E}-06$ & 65 & 0.08 & 2.9 & 0.01 \\
\hline & & $1.0 \mathrm{E}-06$ & $1.0 \mathrm{E}-03$ & 179 & 0.22 & 6.5 & 0.03 \\
\hline & & $1.0 \mathrm{E}-03$ & 20. & 567 & 0.70 & 213 & 0.96 \\
\hline & & 1.0E-09 & 20. & 811 & 1.00 & 222 & 1.00 \\
\hline \multirow{4}{*}{ V19 } & \multirow{4}{*}{30.50} & $1.0 \mathrm{E}-09$ & $1.0 \mathrm{E}-06$ & 22 & 0.11 & 1.0 & 0.01 \\
\hline & & $1.0 \mathrm{E}-06$ & $1.0 \mathrm{E}-03$ & 29 & 0.15 & 1.1 & 0.02 \\
\hline & & $1.0 \mathrm{E}-03$ & 20. & 141 & 0.74 & 63.6 & 0.97 \\
\hline & & 1.0E-09 & 20. & 192 & 1.00 & 65.6 & 1.00 \\
\hline
\end{tabular}

Table 2. Integrals of the spectra measured on CASTOR lids

\begin{tabular}{|c|c|c|c|c|c|c|c|}
\hline CASTOR & $\begin{array}{c}\boldsymbol{R P} \\
{[\mathrm{kW}]}\end{array}$ & $\begin{array}{c}\boldsymbol{E}_{\boldsymbol{m i n}} \\
{[\mathrm{MeV}]}\end{array}$ & $\begin{array}{c}\boldsymbol{E}_{\boldsymbol{m a x}} \\
{[\mathrm{MeV}]}\end{array}$ & $\begin{array}{c}\dot{\boldsymbol{\Phi}} \\
{\left[\mathrm{cm}^{-2} \cdot \mathrm{s}^{-1}\right]}\end{array}$ & $\dot{\Phi}_{\text {rel }}$ & $\begin{array}{l}\dot{\boldsymbol{H}}^{*}(\mathbf{1 0}) \\
{[\mu \mathrm{Sv} / \mathrm{h}]}\end{array}$ & $\dot{H}^{*}(10)_{r e l}$ \\
\hline \multirow{4}{*}{$440 / 84$} & \multirow{4}{*}{12.78} & $1.0 \mathrm{E}-09$ & $1.0 \mathrm{E}-06$ & 67 & 0.11 & 2.9 & 0.03 \\
\hline & & $1.0 \mathrm{E}-06$ & $1.0 \mathrm{E}-03$ & 56 & 0.09 & 2.0 & 0.02 \\
\hline & & $1.0 \mathrm{E}-03$ & 20. & 491 & 0.80 & 109.8 & 0.96 \\
\hline & & $1.0 \mathrm{E}-09$ & 20. & 613 & 1.00 & 114.8 & 1.00 \\
\hline \multirow{4}{*}{ 440/84M } & \multirow{4}{*}{18.34} & $1.0 \mathrm{E}-09$ & $1.0 \mathrm{E}-06$ & 22 & 0.24 & 1.0 & 0.08 \\
\hline & & $1.0 \mathrm{E}-06$ & $1.0 \mathrm{E}-03$ & 21 & 0.23 & 0.8 & 0.07 \\
\hline & & $1.0 \mathrm{E}-03$ & 20 . & 48 & 0.53 & 10.3 & 0.85 \\
\hline & & 1.0E-09 & 20. & 90 & 1.00 & 12.0 & 1.00 \\
\hline
\end{tabular}

Table 3. Dosimetric data measured around CASTOR casks

\begin{tabular}{|c|c|c|c|c|c|c|}
\hline \multirow{2}{*}{ Instrument } & \multirow{2}{*}{ Quantity } & \multicolumn{2}{|c|}{ CASTOR 440/84 } & \multicolumn{2}{c|}{ CASTOR 440/84M } & CASTOR V-19 \\
\cline { 3 - 7 } & $\begin{array}{c}1 \mathrm{~m} \text { above } \\
\text { the floor } \\
\text { among } 4\end{array}$ & $\begin{array}{c}20 \mathrm{~cm} \text { above } \\
\text { the lid }\end{array}$ & $\begin{array}{c}1 \mathrm{~m} \text { above } \\
\text { the floor } \\
\text { among } 4\end{array}$ & $\begin{array}{c}20 \mathrm{~cm} \text { above } \\
\text { the lid }\end{array}$ & $\begin{array}{c}1 \mathrm{~m} \text { above the } \\
\text { floor between } 2\end{array}$ \\
\hline BSS & RP $[\mathrm{kW}]$ & 48.92 & 12.78 & 65.68 & 18.34 & 30.50 \\
\hline \multirow{2}{*}{ LB 6411 } & $\dot{H}^{*}(10)[\mu \mathrm{Sv} / \mathrm{h}]$ & 272 & 115 & 222 & 12.0 & 38.1 \\
\hline \multirow{2}{*}{ FHT 752 } & $\dot{H}^{*}(10)[\mu \mathrm{Sv} / \mathrm{h}]$ & 403 & 140 & 199 & 14.1 & 50 \\
\cline { 2 - 7 } & $\mathrm{LB} / \mathrm{BSS}$ & 1.48 & 1.22 & 1.12 & 1.18 & 1.31 \\
\hline RDS-200 & $\dot{H}^{*}(10)[\mu \mathrm{FHT} / \mathrm{h}]$ & 684 & 302 & 322 & 32.6 & - \\
\hline & $\dot{H}^{*}(10)[\mu \mathrm{BSS} / \mathrm{h}]$ & 45.2 & 4.48 & 52.5 & 2.2 & 44.3 \\
\hline
\end{tabular}


[2] M. Kralik, V. Kulich and J. Studeny, Neutron spectrometry at the interim storage facility for spent nuclear fuel, Nucl. Instrum. Methods Phys. Res. A 476 (2002), pp. 423-428.

[3] M. Kralik, V. Kulich, J. Studeny and P. Pokorny, Dosimetry at an interim storage for spent nuclear fuel, Rad. Prot. Dos. 126 (2007), pp. 549-554.

[4] M. Reginatto, The few channel unfolding programs in the UMG package, UMG package, version 3.3, 1 March 2004, PTB Braunschweig.
[5] ICRP 74, Annals of the ICRP 26 (1996) No. 3/4 /, Conversion Coefficients for use in Radiological Protection against External Radiation.

[6] ICRU 57, ICRU Report 57 (1998), Conversion Coefficients for use in Radiological Protection against External Radiation.

[7] IEC 61005 (2003), Radiation protection instrumenttation - Neutron ambient dose equivalent (rate) meters. 